\title{
EVALUATION OF THREE EVAPORATIVE COOLING PADS FROM AGRICULTURAL WASTES
}

\author{
S. A. Tayel ${ }^{(1)}$, M. A. Mosallam ${ }^{(2)}$ and A. M. Mousa ${ }^{(3)}$
}

\section{ABSTRACT}

A Gable even span greenhouse $3 \times 2 \times 2.6 m$ was constructed. This greenhouse was equipped with an evaporative cooling system. Three waste materials were used as pads for this system. These materials are: Flax plant residues, Luffa plant residues and the third material was a combination of the two materials. Each pad material was tested under three thicknesses. These thicknesses are 4, 8 and $12 \mathrm{~cm}$. Each thickness for each of the three materials was tested under three velocities. These velocities are $0.45,0.65$ and $0.90 \mathrm{~m} / \mathrm{s}$. The experiments were carried out during august 2008 where the mean ambient temperature was $35.8{ }^{\circ} \mathrm{C}$ and the mean relative humidity was $39.6 \%$. Mean cool temperatures at the pads were 25.5, 25.9 and $26.6{ }^{\circ} \mathrm{C}$ for Flax plant residues, Luffa Plan residues and the combined material respectively. Highest cooling efficiency was $97.7 \%$ when using Flax plant residues pad material with thickness $12 \mathrm{~cm}$ at pad face air velocity $0.65 \mathrm{~m} / \mathrm{s}$. For Luffa material the highest cooling efficiency was $91 \%$ at used pad thickness $12 \mathrm{~cm}$ and pad face air velocity $0.45 \mathrm{~m} / \mathrm{s}$. For the Combined material the highest cooling efficiency was $94.4 \%$ at used pad thickness $12 \mathrm{~cm}$ and pad face air velocity $0.45 \mathrm{~m} / \mathrm{s}$. The research concluded to that the recommended pad is Flax and the recommended thickness for the system is $12 \mathrm{~cm}$ and the recommended pad face velocity is $0.45 \mathrm{~m} / \mathrm{s}$. The correcting Length factor " $K$ " for the greenhouses of length " $L$ " where: $3 m \leq L<6 m$ was determined roughly by the eye carve fitting.

\section{INTRODUCTION}

7 he temperature degrees during summer in Egypt reach high values. These high values are not suitable for growing certain agricultural plants in the field and make the conditions harder for the plants inside the greenhouse.

(1) Prof., Agr. Eng. Dept., Fac. of Agr., AL-Azhar Univ.

(2) Assoc. Prof., Agr. Eng. Dept., Fac. of Agr., AL-Azhar Univ.

(3) Demonstrator, Agr. Eng. Dept., Fac. of Agr., AL-Azhar Univ. 
Reducing temperature inside the greenhouse is crucial for the possibility of producing agricultural plants during summer. Also Egyptian summer has a low relative humidity, these tow factors (high temperature and low relative humidity) can handicap the production of some agricultural plants. Lowering temperature and rising relative humidity inside the greenhouses is, so, important (Hassan, 1999). Evaporative cooling systems carry out such a task. The use of artificial pads for evaporative cooling system may be expensive. The cost of cooling by the evaporative cooling systems may be lowered by using local waste materials as pads. This research aims to the investigating the performance of some waste materials used as pads for the evaporative cooling systems.

\section{REVIEW OF LITERATURE}

Evaporative cooling system consists of a fan on one side of the greenhouse and a pad on the opposite side. The principle of the system is applying a running water stream over the pad and consequent withdrawal of air through it by a fan (or fans) on the opposite side. In this system, water evaporates taking away heat (sensible heat) from the air thus reducing its temperature. This sensible heat is converted into latent heat of evaporated water. So, the process is a constant enthalpy process, Tiwari (2003). Evaporative cooling system produces two changes in the condition of the air exiting the pad: the air becomes cooler and its humidity is raised, Sethi and Sharma (2007). Darwesh et al. (2007), Chandra (2000), Papa and El- Galabi (1997) and Alchalabi (1996) mentioned that the factors affecting evaporative cooling system are: 1Weather conditions. 2- Pad material. 3- Pad thickness and density. 4- Pad face air velocity. Ashrae (1992) reported that evaporative cooling performance depends on the prevailing outdoor dry and wet bulb temperature. Hellickson and Walker. (1983) mentioned that manufacturers have tried pad materials of wood, metal, glass and more recently, plastic and cement. Porous materials generally provide the most efficient cooling. Sharaf (1994): used pads that made manually from two different materials. First pad material was from leaf fibers of ornamental palm and the second was from common reed plant. He found that the first 
pad material was better in cooling than the second pad material. Bottcher et al. (1992), used $15 \mathrm{~cm}$ thick vertical pads of cellulose materials. They found that the evaporative cooling efficiency of the pads were $80 \%$ to $89 \%$. An average temperature reduction of about $6.7^{\circ} \mathrm{C}$ was obtained when outside temperature was $32^{\circ} \mathrm{C}$. Sharaf (1994), used four pad thicknesses namely: 2, 4, 6, and $8 \mathrm{~cm}$. He found that cooling efficiency increased by increasing pad thickness. Darwesh et. al. (2007) investigated the performance criteria of rice straw and palm leaf fibers as pad materials of the evaporative cooling system. The highest value of temperature reduction was achieved with $15 \mathrm{~cm}$ pad thick and $0.5 \mathrm{~m} / \mathrm{s}$ pad face air velocity. While the lowest value occurred with $3 \mathrm{~cm}$ pad thick and $0.5 \mathrm{~m} / \mathrm{s}$ pad face air velocity. Alchalabi (1996), made a comparison between 10 and $20 \mathrm{~cm}$ thicknesses of two types of vertical pad material. He mentioned that the best selection was when using pad with thickness of $20 \mathrm{~cm}$ with $1.5 \mathrm{~m} / \mathrm{s}$ pad face air velocity. Cooling efficiencies were $91 \%$ and $65 \%$ at 20 and $10 \mathrm{~cm}$ pad thick, respectively. Liao and Kara (2002) studied three different vertical pad thicknesses namely 5,10 , and $15 \mathrm{~cm}$. these pads were made of an industrial material. They found that the thicker the pad is the higher the cooling efficiency. Durward and Wiersma (1974) Suggested that vertical pads should have a density of approximately $32 \mathrm{~kg} / \mathrm{m}^{3}$. They also recommended that padface air velocity should not exceed $1.25 \mathrm{~m} / \mathrm{s}$. They mentioned that researchers indicated that pad-fan air velocities above $1.27 \mathrm{~m} / \mathrm{s}$ results in excessive static pressure loss with little increase in saturation efficiency. Liao and Kara (2002) found that pad face air velocity greater than 1.75 $\mathrm{m} / \mathrm{s}$ tended to pull free water into the air stream. Welchert and Wiersma (1972) said that the optimum air velocity at the pad face is about 1.02 $\mathrm{m} / \mathrm{s}$. They recommended that pad-face air velocity should not exceed $1.25 \mathrm{~m} / \mathrm{s}$, because of the increase of static pressure loss and the tendency to pull free water into the air stream.

\section{MATERIALS AND METHODS}

A greenhouse was constructed at the Agr. Eng. Dept., Fac. of Agriculture, Al- Azhar Univ., Nasr City, Cairo. The constructed greenhouse, Fig. (1), was gable even span type in shape. Length and 
width of it are 3 and $2 \mathrm{~m}$ respectively while its maximum height is $2.6 \mathrm{~m}$. Angle of inclination of the roof is $30^{\circ}$. The greenhouse was covered with single polyethylene plastic cover $(120 \mu \mathrm{m}$ thick). The longitudinal axis of the greenhouse was oriented $(\mathrm{N}-\mathrm{S})$ direction. Metal tubes of diameter $25 \mathrm{~mm}$ were used in constructing the green house. A rectangular opening was made in the frame of the greenhouse for the frame of the pad (the frame of the pad was used to locate the evaporative cooling pad). Dimensions of the opening are $2 \times 1 \mathrm{~m}$. The opening orientation was at the northern wall of the greenhouse. An opening on the opposite direction of that of the frame the pad, southern direction, of dimensions of $0.40 \times$ $0.40 \mathrm{~m}$ was made for the fan. The frame of the pad was made from wood and covered with a mesh of wire. The mesh is formed of squares of $1 \times 1$ $\mathrm{cm}^{2}$.The experimental greenhouse was constructed on the top of a building of one floor. This top is formed from concrete. To simulate the existence of an agricultural soil, the greenhouse was constructed above an artificial soil. This artificial soil was formed from sand (20 cm depth). This soil was wetted at the begin of each experiment done during this work. The greenhouse was equipped with an evaporative cooling system. The components and specifications of the system are:

1- An exhaust axial flow fan of volumetric flow rate of $120 \mathrm{~m}^{3} / \mathrm{min}$. The fan velocity was controlled with the help of a speed regulator.

2- Three waste materials were used as evaporating cooling pad substances (Fig. 2) namely: Flax plant residues, Luffa plant residues (Luffa which is not desirable by the consumer for its bad qualities) and a combination of Flax residues and Luffa residues. This combination is formed of layers: a layer of Flax, above which a layer of Luffa and so on. The thickness of each layer is $10 \mathrm{~cm}$.

3- Water cycle of the evaporative cooling system consisted of a tank of volume of 723 liter. A $0.3 \mathrm{~kW}$ centrifugal pump whose maximum discharge is $27 \mathrm{~L} / \mathrm{min}$ and its maximum head is $12 \mathrm{~m}$. Polyethylene tubes of diameter 1 inch. Distributor and a steel gutter as shown Fig. (3). Water is pumped from the tank to the mid-length of the distributor through the polyethylene tubes. Water falls freely from the distributor onto the pad. Water flow through the pad and falls freely onto the gutter. The gutter is slightly inclined and ends above the water tank. 


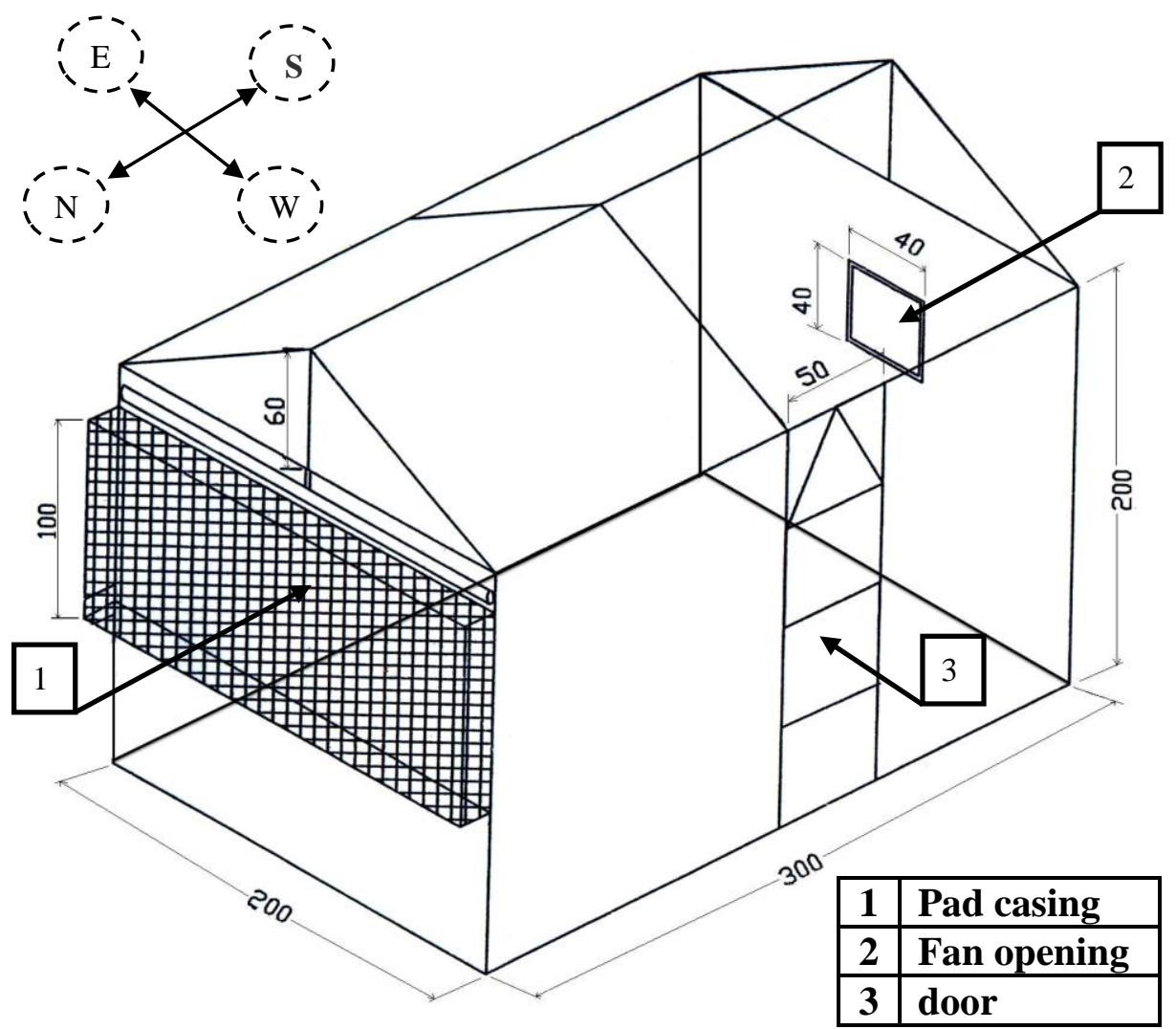

Fig. (1): The constructed greenhouse. (Dim in $\mathrm{cm}$ ).
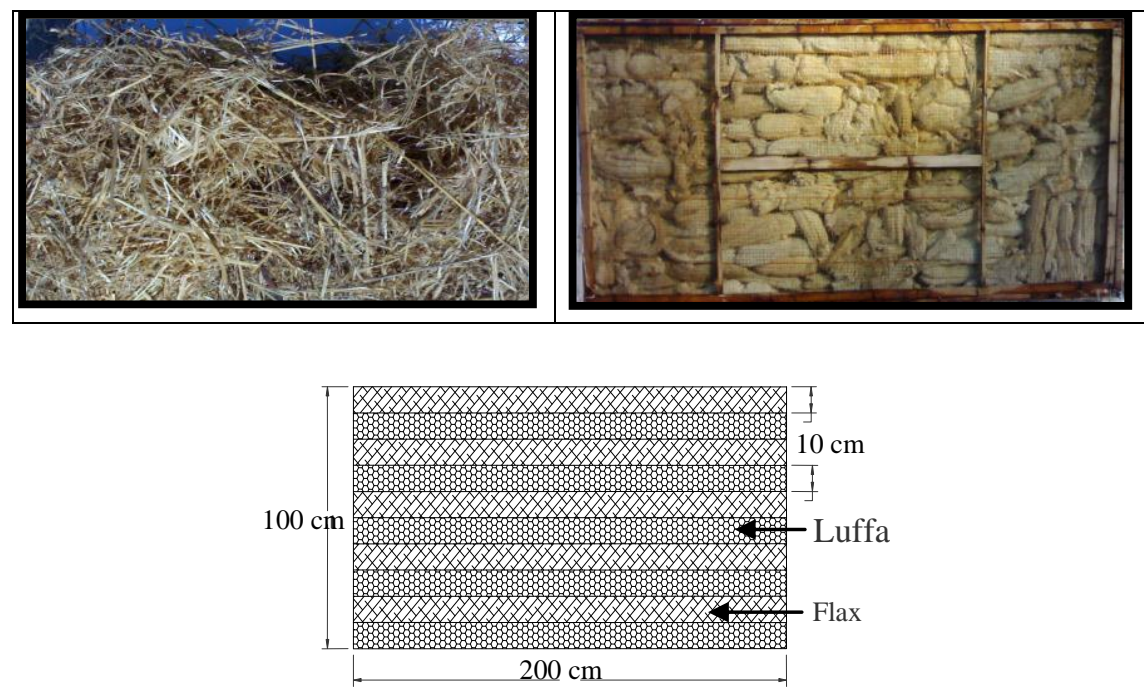

Fig. (2): The three tested pad materials. Upper left: Flax, Upper right Luffa, Lower: Combined. 


\section{Variables of the study:}

1- Three pad materials were tested: Flax plant residues, Luffa plant residues and a combination of them.

2- For each material three thicknesses were tested namely 4,8 and $12 \mathrm{~cm}$.

3- Each thickness of the three used materials was operated under three pad face air velocities. The velocities are $0.45,0.65$ and $0.90 \mathrm{~m} / \mathrm{s}$.

The combination resulting from the mentioned variables is 27 treatments.

Dry and wet bulb temperatures were measured inside and outside the greenhouse. Dry bulb temperatures were measured with a thermocouple (Cole Palmer of model No: $8528-40 \mathrm{~K}$ ) of accuracy of $0.1{ }^{\circ} \mathrm{C}$. Wet bulb temperatures were measured using a mercury thermometer with a wick. Locations for measuring dry and wet bulb temperature inside the greenhouse were according to El-Zan (2008) as shown in Fig. (4). Dry bulb temperatures were measured at plane of symmetry of the greenhouse at nine locations denoted by $T_{n}$, where " $n$ " denotes an integer from 1 to 9 . Wet bulb temperatures were measured at this plane at three locations denoted by $\mathrm{H}_{n}$, where "n" denotes an integer from 1 to 3. From Fig. (4), cooling temperature (temperature in front of the pad), was taken as the mean of the three readings. Each of the temperatures at the mid of the greenhouse and at the fan was taken as the mean of the three readings.

Pad face air velocity was measured using a Turbometer of accuracy of $0.01 \mathrm{~m} / \mathrm{s}$. pad face air velocity was measured at five points in front of the pad as shown in Fig. (5). Air velocity at the face of the pad was taken as the mean of the five readings.

Pads were used in the evaporative cooling system at a constant bulk density of $32 \mathrm{~kg} / \mathrm{m}^{3}$ according to Wiresma (1969) and El-Zan (2008). Frame of the pad is of constant surface area $\left(2 \mathrm{~m}^{2}\right)$ and for a specific thickness of the pad, volume of the pad can be calculated. From the volume and bulk density, required mass of the pad was determined.

Cooling efficiency “ $\boldsymbol{\eta}$,, was calculated according to Ashrae (1983):

$$
\eta=\frac{T o-T i}{T o-T w}
$$




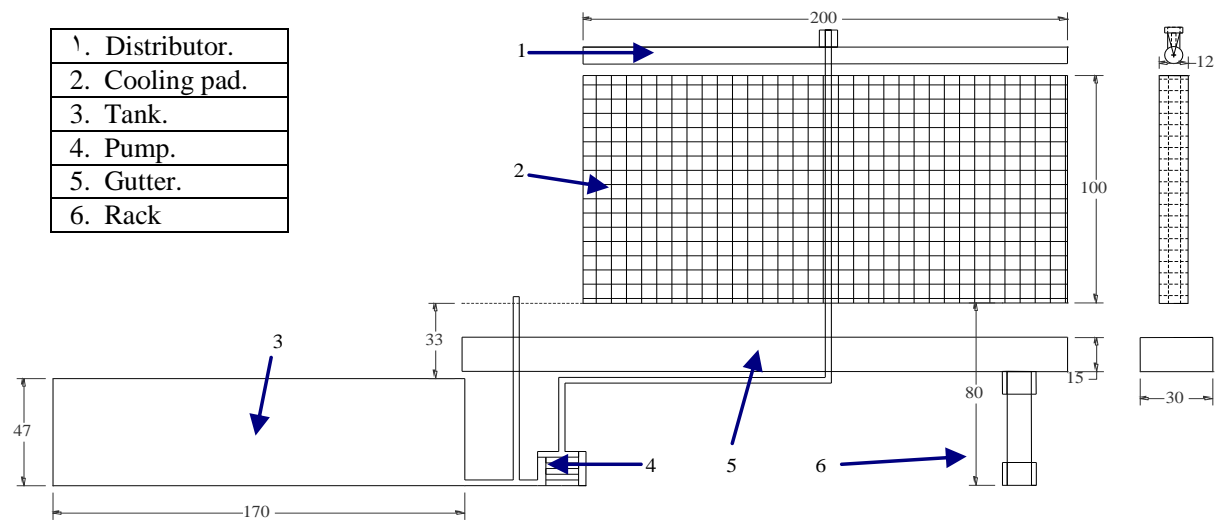

Fig. (3): Water cycle of the evaporative cooling system.

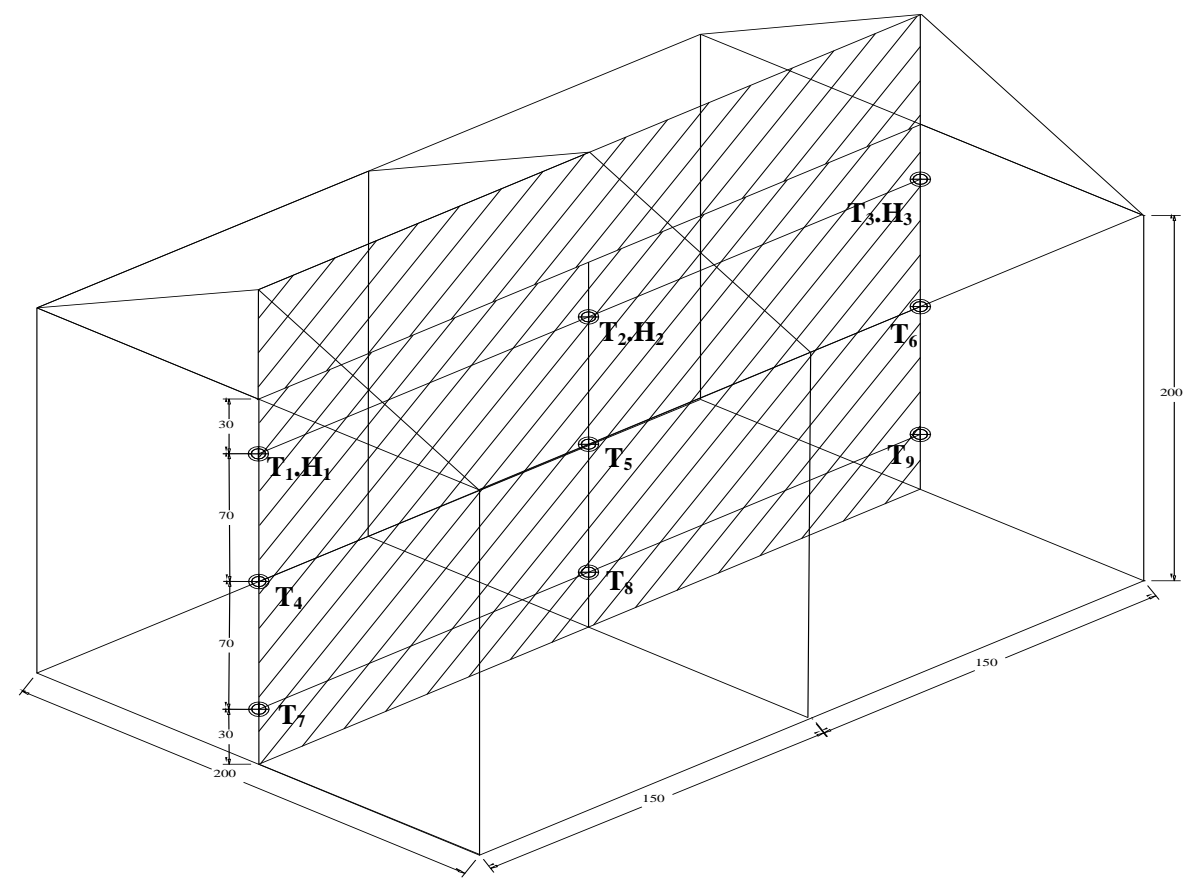

Fig. (4): Locations of measuring temperature $\left(T_{n}\right)$ and relative humidity $\left(\mathrm{H}_{\mathrm{n}}\right)$ inside the greenhouse. 


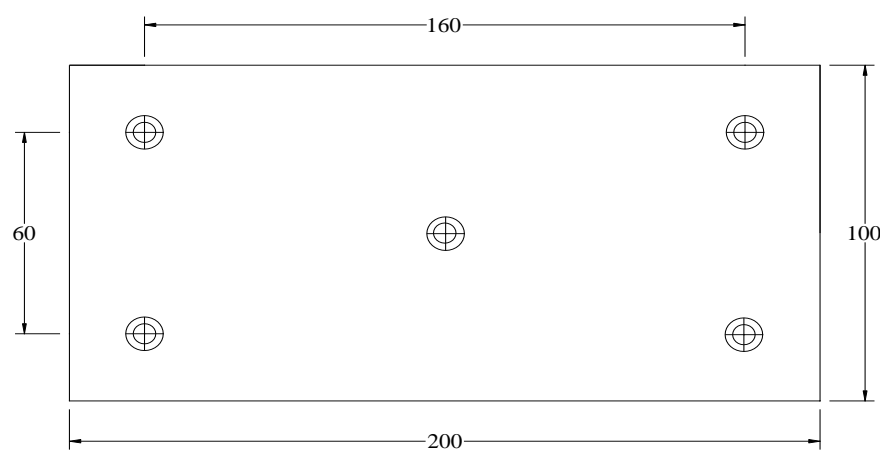

Fig. (5): Locations of measuring pad face air velocity. (Dim in $\mathrm{cm}$ )

Where:

$\boldsymbol{\eta}$ : cooling efficiency, (\%);

$\mathrm{T}_{\mathrm{o}}$ : temperature of the outside air, $\left({ }^{\circ} \mathrm{C}\right)$;

$\mathrm{T}_{\mathrm{i}}$ : temperature of the cooled air, $\left({ }^{\circ} \mathrm{C}\right)$;

$\mathrm{T}_{\mathrm{w}}$ : wet-bulb temperature of outside air, $\left({ }^{\circ} \mathrm{C}\right)$.

The experiments started on 31 July 2008 and ended on 28 Augusts 2008 (lasted for 28 days).

\section{RESULTS AND DISCUSSION}

Table (1) shows the values of the highest and lowest cooling efficiencies for the three tested pad materials (at the corresponding thicknesses, pad face velocities, outside and inside temperatures, outside and inside relative humidities). From Table (1), for pad material Flax plant residues, the highest value of cooling efficiency was $97.7 \%$ at the thickness $12 \mathrm{~cm}$ and pad face air velocity $0.65 \mathrm{~m} / \mathrm{s}$. For pad material Luffa plant residues, the highest value of cooling efficiency was $91 \%$ at the thickness $12 \mathrm{~cm}$ and pad face air velocity $0.45 \mathrm{~m} / \mathrm{s}$. For the Combined pad material, the highest value of cooling efficiency is $94.4 \%$ at used thickness $12 \mathrm{~cm}$ and pad face air velocity $0.45 \mathrm{~m} / \mathrm{s}$.

Fig. (6) Shows the relation between pad face air velocities and cooling efficiency " $\eta_{V}^{F}, \eta_{V}^{L}$ and $\eta_{V}^{C}$ " (superscript denotes name of the material: F, 
Table (1): The values of the higest and lowest cooling efficiencies for the three tested pad materials.

\begin{tabular}{|c|c|c|c|c|c|c|c|c|}
\hline 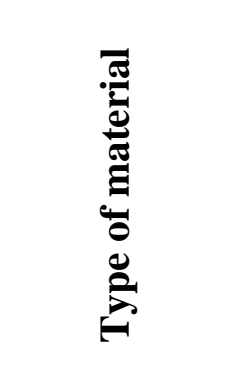 & \multicolumn{2}{|c|}{ 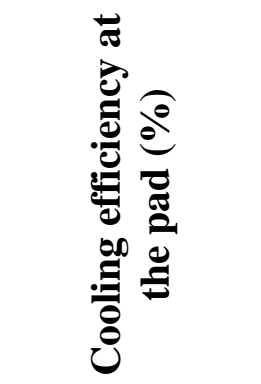 } & 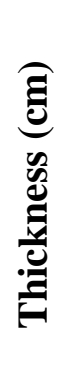 & 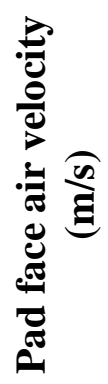 & 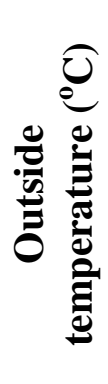 & 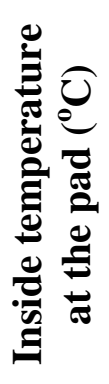 & 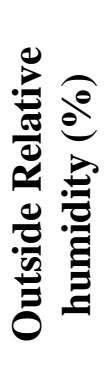 & 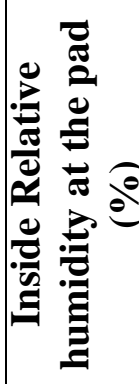 \\
\hline \multirow{2}{*}{$\begin{array}{c}\text { Flax Plant } \\
\text { Residues }\end{array}$} & $\begin{array}{c}\text { The } \\
\text { highest }\end{array}$ & 97.7 & 12 & 0.65 & 36.2 & 24.6 & 38.8 & 83.5 \\
\hline & $\begin{array}{c}\text { The } \\
\text { lowest }\end{array}$ & 78.1 & 4 & 0.90 & 35.9 & 26.4 & 36.5 & 83.0 \\
\hline \multirow{2}{*}{ Luffa Plant } & $\begin{array}{c}\text { The } \\
\text { highest }\end{array}$ & 91.0 & 12 & 0.45 & 34.7 & 25.7 & 45.6 & 83.9 \\
\hline & $\begin{array}{c}\text { The } \\
\text { lowest }\end{array}$ & 76.7 & 4 & 0.90 & 34.8 & 26.1 & 39.3 & 81.5 \\
\hline \multirow{2}{*}{ Combination } & $\begin{array}{c}\text { The } \\
\text { highest }\end{array}$ & 94.4 & 12 & 0.45 & 36.2 & 25.8 & 41.5 & 87.9 \\
\hline & $\begin{array}{c}\text { The } \\
\text { lowest }\end{array}$ & 68.9 & 4 & 0.90 & 35.6 & 27.4 & 37.8 & 81.3 \\
\hline
\end{tabular}

L, and C denote Flax, Luffa and Combined respectively. The lower script $\mathrm{V}$ denotes the velocity) under the range of the tested thickness (4-12 $\mathrm{cm}$ ) for the three tested pad material where efficiency of each material at a certain velocity is the mean of the values of three efficiencies, each corresponds to one of the three tested thicknesses. The relation of each of the three pad materials agree with a decreasing linear function with high R-squared value. For each pad material, under the range of the tested thicknesses, the velocity $0.4 \mathrm{~m} / \mathrm{s}$ gave the highest efficiency.

Fig. (7) shows the relation between pad thickness and cooling efficiency $\eta_{t h}^{F}, \eta_{t h}^{L}$ and $\eta_{t h}^{C}$ (the lower script "th" denote the thickness).

Under the range of tested velocities $(0.45-0.90 \mathrm{~m} / \mathrm{s})$ for three tested pad material where efficiency of each material at a certain thickness is the 

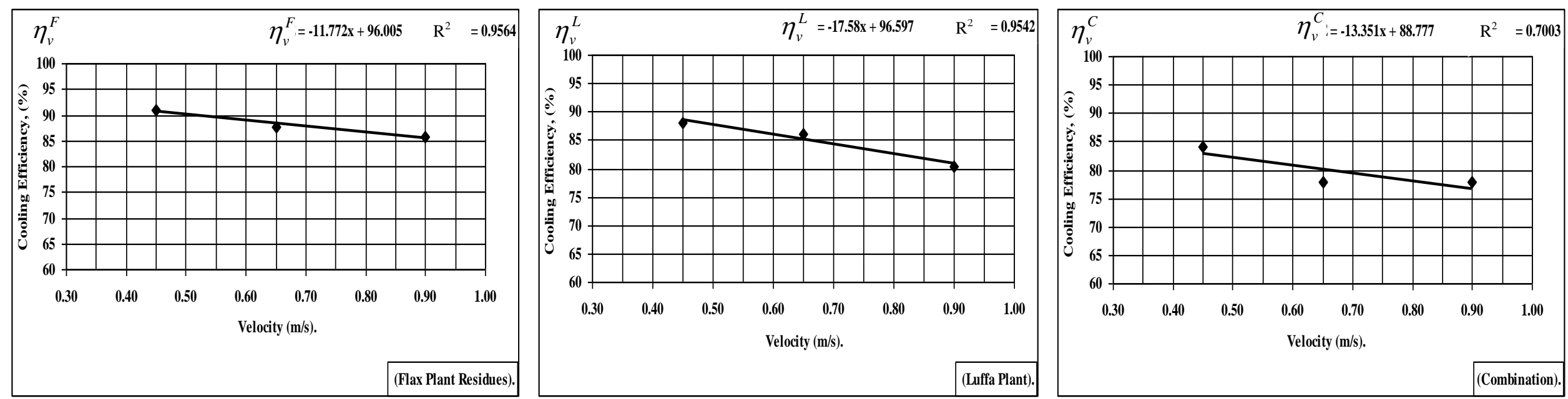

Fig. (6): The relation between pad face air velocities and cooling efficiency for the three tested pads.
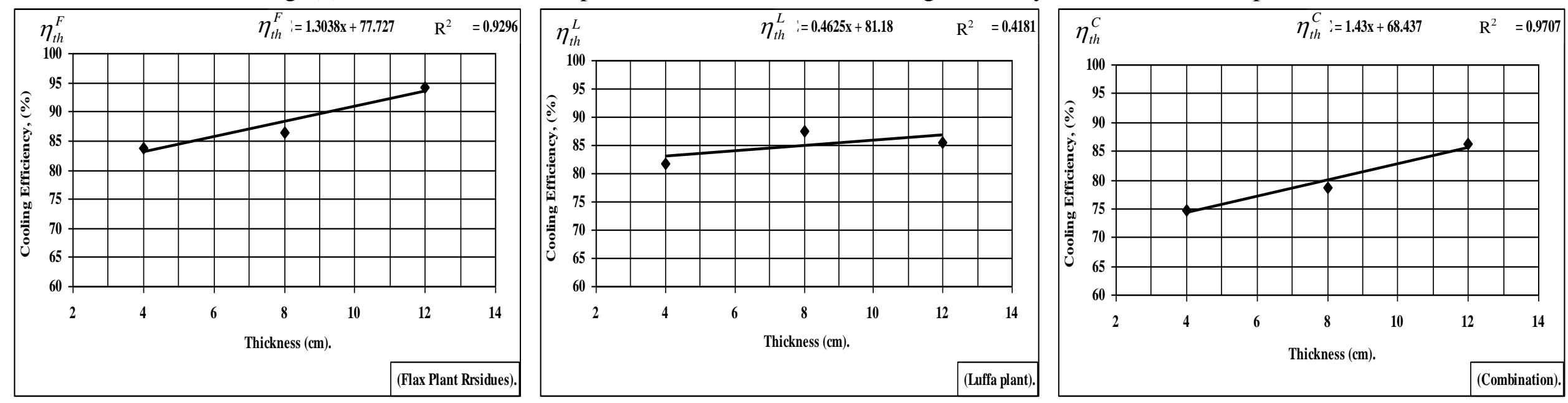

Fig. (7): The relation between pad thicknesses and cooling efficiency for the three tested pads. 
mean of the values of three efficiencies, each corresponds to one of the three tested velocities. The relation of each of the three pad materials agree with an increasing liner function with high R-squared value. For each pad material, under the range of the tested velocities, the thickness $12 \mathrm{~cm}$ gave the highest efficiency.

Fig. (8) shows the relation between each pad material and mean cooling efficiency " $\eta_{m}^{\text {material }}$ " (subscript " $m$ " denote the mean) under tested thicknesses and velocities. The mean cooling efficiency for each material is the mean value of nine values of efficiencies corresponds to ( 3 thicknesses $\mathrm{x} 3$ velocities). The figure shows that Flax has the greatest mean cooling efficiency while the combined has the lowest one.

Fig. (9) shows the relation between pad face air velocity and waste cooling efficiency " $\eta_{V}^{F L C}$ " (superscript FLC denote the three tested pad materials, Flax, Luffa and combined, taken as a waste). The waste cooling efficiency at a certain velocity is the mean value of nine values of efficiencies corresponds to ( 3 materials $\mathrm{x} 3$ thicknesses). The relation agrees with a decreasing linear function with high $\mathrm{R}$-squared value. For the waste tested, under the range of the tested thicknesses, the velocity 0.4 $\mathrm{m} / \mathrm{s}$ gave the highest efficiency.

Fig. (10) shows the relation between pad thickness and waste cooling efficiency $" \eta_{t h}^{F L C} "$. The waste cooling efficiency at a certain thickness is the mean value of nine values of efficiencies corresponds to (3 materials $\mathrm{x}$ 3 velocities).

The relation agrees with an increasing linear function with high R-squared value. For the waste tested, under the range of the tested velocities, the thickness $12 \mathrm{~cm}$ gave the highest efficiency.

Fig. (11) shows the relation between length (L) alongside the greenhouse (from the pad to the fan) and mean inside temperature over the range of the tested thickness and the range of the three tested velocities for each pad material (the mean is of nine readings) ${ }^{\prime} T_{m}^{F}, T_{m}^{L}$ and $T_{m}^{C}$ “. 

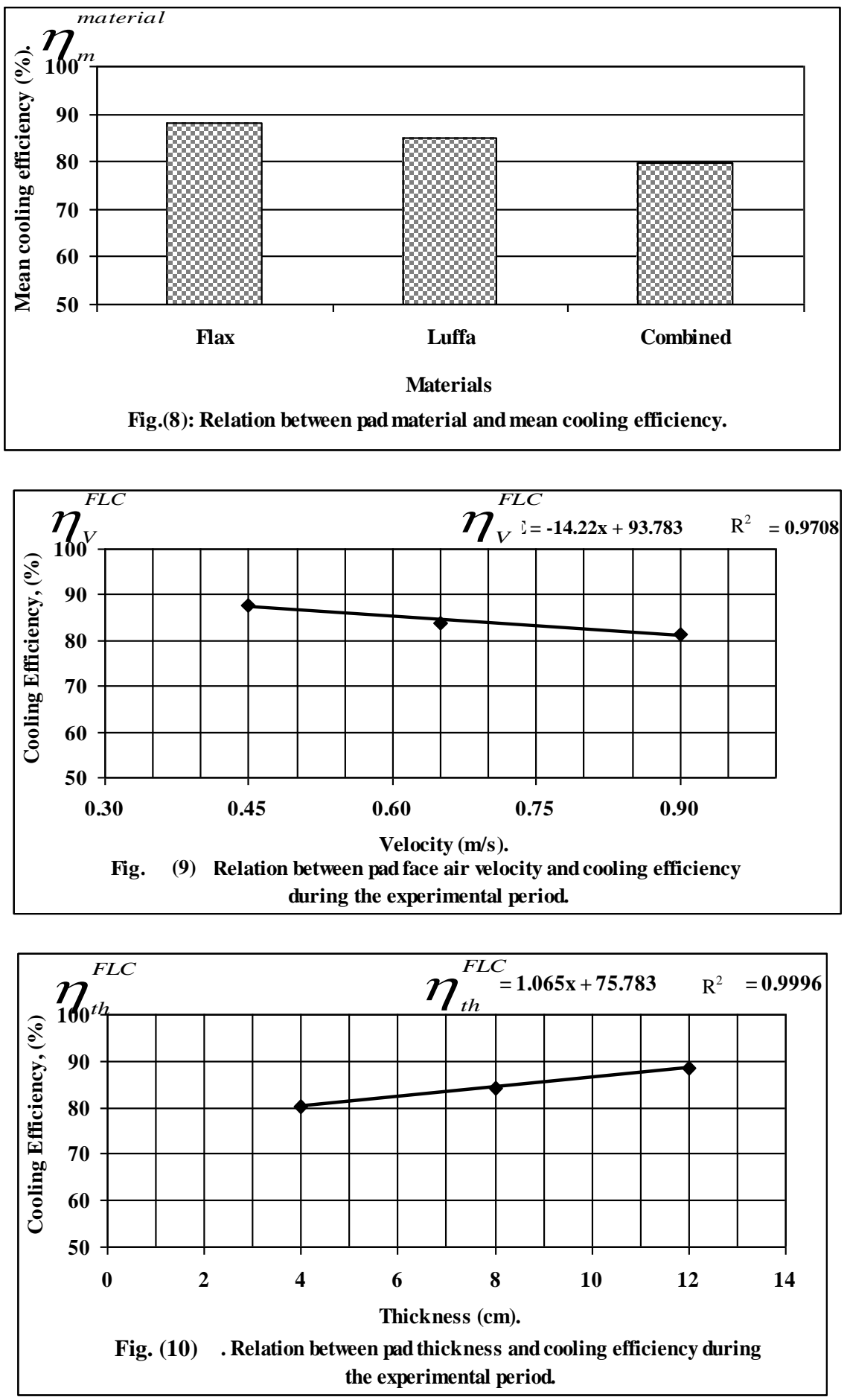

Misr J. Ag. Eng., July 2010 

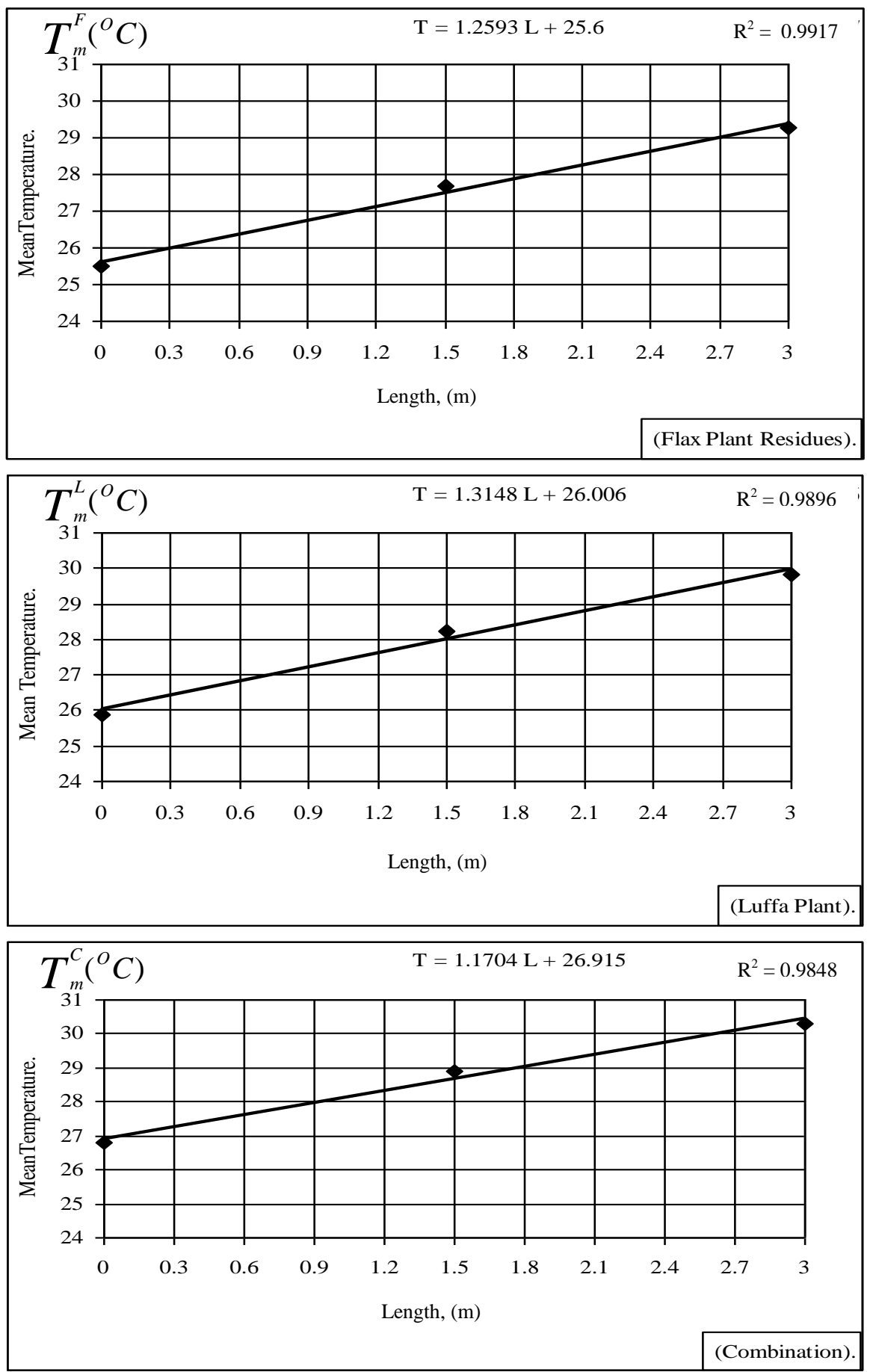

Fig. (11): Relation between length (L) alongside the greenhouse and mean inside temperature for the three tested pads. 
The relation between length of the greenhouse and inside temperature for the three tested pad materials agree with an increasing linear function with high R-squared. The difference between mean temperature at the pad and mean temperature at the fan ranged from 3 to $4{ }^{\circ} \mathrm{C}$.

For the evaporative cooling systems under standard conditions: 1- Level of the greenhouse is $300 \mathrm{~m}$ or less. 2- Intensity of light inside the greenhouse is $58.3 \mathrm{k}$ lux. 3 - The permitted temperature reduction between the pad and the fan is $4{ }^{\circ} \mathrm{C}$. 4- Distance between fan and pad is $30 \mathrm{~m}$, the recommended air flow is $2.5 \mathrm{~m}^{3}$ per minute per $\mathrm{m}^{2}$ of the surface area of the greenhouse. Hassan (1999). A correcting factor " $K$ " concerns the unfulfilled distance (less than $30 \mathrm{~m}$ ) can be obtained from Table (2) in the appendix. This table does not give $\mathrm{K}$ for distances less than $6 \mathrm{~m}$. In case of greenhouses which do not fulfill the conditions 1 through 3, tables give correction factors for each unfulfilled condition. These factors (concern unfulfilled factors 1 through 3) must be multiplied to get one factor (the product factor). Calculating the product factor for the experimental greenhouse [taking its highest values from the corresponding tables, Hassan (1999)] will results in: 1.36 x 1.6 x $0.7=1.52$. The two values of the factors: product factor and " $\mathrm{K}$ " are to be compared and the greater one is to be taken for correcting the required flow air per unit area for the greenhouse. From this study, the Flax straw pad of thickness $12 \mathrm{~cm}$ and at pad face air velocity $0.65 \mathrm{~m} / \mathrm{s}(39 \mathrm{~m} / \mathrm{min}$.) gave the highest efficiency. Area of the tested greenhouse is $6 \mathrm{~m}^{2}$ and area of the tested pad material is $2 \mathrm{~m}^{2}$. The length of the greenhouse is $3 \mathrm{~m}$.

Considering the following relation, Hassan (1999),:

$$
\text { Area of } \operatorname{pad}\left(\mathrm{m}^{2}\right)=\frac{2.5 \frac{\mathrm{m}^{3}}{\min . \mathrm{m}^{2}} \times \text { area of greenhouse }\left(\mathrm{m}^{2}\right) \times \text { factor } K}{\text { velocity }(\mathrm{m} / \mathrm{min} .)}
$$

And from the above data,

$$
2=\frac{2.5 \times 6 \times K}{39} \Rightarrow K=5.2
$$

The aim is to find values of " $K$ " for greenhouses, for the previously specified pad material, of length " $L$ " where: $3 m \leq L<6 m$. As the distance 
of the greenhouse decreases $30 \mathrm{~m}$, the cooled air does not spread through the whole greenhouse but tends to flow in a narrow path from the pad to the fan. The following analysis is based on the thought that as distance from the pad to the fan tends to zero, the required air flow rate tends to infinity such as to spread the whole greenhouse and the relation between " $\mathrm{L}$ " and " $\mathrm{K}$ " is a transformation of the function:

$$
K=\frac{1}{L}
$$

So, plotting [from the table (2)] "K" versus "L" and adding the point (3, 5.2) and drawing a smooth curve between them (the drawn curve resembles the curve of a transformed function $y=1 / x$ ) and plotting, by trial and error some points on the interval $L \in[3,6[$ a curve of the following equation is obtained (Fig. 12):

$$
\mathrm{K}=12.302 \mathrm{~L}^{-0.7779}, \quad \mathrm{R}^{2}=0.92
$$

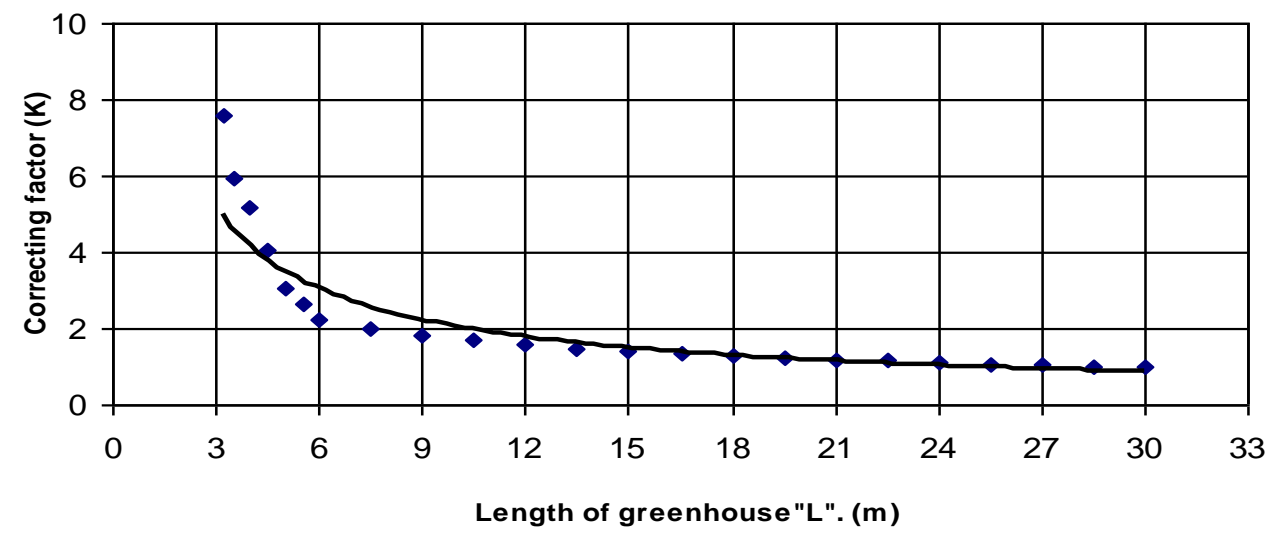

Fig. (12): Relation between length of greenhouse and correcting factor of distance.

From this equation, "K" may be calculated for greenhouses of $3 m \leq L<6 m$ for the previously specified pad material. If the Flax pad is used with $12 \mathrm{~cm}$ thickness and 0.65 pad face velocity (for highest efficiency) and the length of the greenhouse " $L$ " such that $3 m \leq L<6 m$, the user can get area of the pad using the previously mentioned equation. Knowing width of the greenhouse, Height of the pad can be calculated. 


\section{SUMMARY}

A greenhouse (gable even span in shape) was constructed. Length and width of the greenhouse are 3 and $2 \mathrm{~m}$ while its maximum height is $2.6 \mathrm{~m}$. The greenhouse was equipped with an evaporative cooling system. Three waste materials used as evaporative cooling pads. These wastes are: Flax plant residues, Luffa plant residues and a Combined pad material formed from the two materials with ratio $0.5-$ 0.5 . Performance of each of the three pads was investigated under three thickness $(4,8$ and $12 \mathrm{~cm})$ and three pad face air velocities $(0.45,0.65$ and $0.90 \mathrm{~m} / \mathrm{s})$. The results were as follows:

1- The highest cooling efficiency was $97.7 \%$ when using Flax plant residues pad with thickness $12 \mathrm{~cm}$ and pad face air velocity $0.65 \mathrm{~m} / \mathrm{s}$. For Luffa residues the highest cooling efficiency was $91 \%$ at used pad thickness $12 \mathrm{~cm}$ and pad face air velocity $0.45 \mathrm{~m} / \mathrm{s}$. For the Combined material the highest cooling efficiency was $94.4 \%$ at used pad thickness $12 \mathrm{~cm}$ and pad face air velocity $0.45 \mathrm{~m} / \mathrm{s}$

2- The relation between cooling efficiency and velocity (under the range of the tested thicknesses) found to be liner (decreasing) with high correlation coefficient for all used pads. Also; the relation between cooling efficiency and thickness (under the range of the tested velocities) found to be liner (increasing) with high correlation coefficient for all used pads.

3- Under the tested thickness range $(4-12 \mathrm{~cm})$ and the tested velocity range $(0.45-0.90 \mathrm{~m} / \mathrm{s})$, the highest mean cooling power was for Flax followed by Luffa followed by Combined.

4- Under the range of the tested thickness and considering the three tested material as one waste, the relation between cooling efficiency and pad face air velocity was liner (decreasing) with high correlation coefficient while, Under the range of the tested velocities and considering the three tested material as one waste, the relation between cooling efficiency and thickness was liner (increasing) with high correlation coefficient.

5- The relation between average temperature (average temperature under the three tested thicknesses and the three tested velocities) and 
greenhouse length for the three tested materials, found to be liner (increasing) with high correlation coefficient.

6- $12 \mathrm{~cm}$ was the best thickness used $0.45 \mathrm{~m} / \mathrm{s}$ was the best velocity used.

7- The correcting Length factor " $K$ " for the greenhouses of length " $L$ " where: $3 m \leq L<6 m$, Was determined roughly, for Flax pad with 12 $\mathrm{cm}$ thickness under face velocity $0.65 \mathrm{~m} / \mathrm{s}$, by the eye carve fitting method by the following equation:

$$
\mathrm{K}=12.302 \mathrm{~L}^{-0.7779}, \quad \mathrm{R}^{2}=0.92
$$

\section{REFERANCES}

Alchalabi, D. A. (1996). Computer - aided design for evaporative cooler system and estimating number of air coolers in poultry houses. J. AMA, 27(4):49-52, 55.

ASHRAE. (1992). Evaporative air-cooling in Equipment. Handbook, Ch: 19, Atlanta, GA: American Society of Heating, Refrigeration and Air-Conditioning Engineers, Inc., Atlanta, GA 30329.

ASHRAE. (1983). Evaporative Air-cooling Equipment. Chapter 4. Equipment Handbook. American Society of Heating, Refrigeration and Air-Conditioning Engineers. Atlanta, Georgia, USA.

Bottcher, R. W.; L. B. Drigger.; T. A. Carter and A. O. Hobbs (1992). Filed evaluation of reflective bubble-pack isolation in broiler house. Journal of applied engineering, 8 (3): 369-374.

Chandra, P. (2000). Short course on greenhouse cooling in tropical regions. Division of agricultural engineering, I.A.R.I, New Delhi.

Darwesh , M.; S. Abouzaher.; T. Fouda and M. Helmy (2007). Effect of using pad manufactured from agricultural residues on the performance of evaporative cooling system. Misr. J.Agr. Eng, 24(4):1023-1041.

Durward, S. B.; and F. Wiersma (1974). Design criteria of evaporative cooling for agricultural application. ASAE, Dec., paper No: 74 4527.

El-Zan, N. M (2008). Effect of roof water flow and new evaporative cooling pads on cooling performance inside the greenhouse. MSC. thesis Fac. of Agric. Kafer ElSheikh Univ. 
Hassan, A. A (1999). Technology of Greenhouses (In Arabic). Hand book - academic library for publishing and distribution. 535 P.P: 111142.

Hellickson, M. L and J.N. Walker (1983). Ventilation of agricultural structures. ASAE. St. joseph, MI. 49085-9659.

Liao, C. M. and H. Kara (2002). Wind tunnel modeling the system performance of alternative evaporative cooling pads in Taiwan region. Building and Environment, No.37, p.p: 177-187.

Papa, A. A. and D. A. El-Galabi (1997). Constructed palm fibers pads of evaporative cooling. Transaction of the ASAE, 71 (26): 1-14.

Sethi, V. P. and S. K. Sharma (2007). Survey of cooling technologies for worldwide agricultural greenhouse applications. Solar Energy. 81, 1447-1459.

Sharaf, S. M. (1994). Reducing heat stresses in poultry house under local conditions. Menofiya. J. Agric. Res, 6 (1):2937-2955.

Tiwari, G. N. (2003). Greenhouse Technology for Controlled Environment. Narosa Publishing House, India, PP 325-327.

Welchert. W. T. and F. Wiersma (1972). Evaporative cooling for laying house in Arisona. ASAE. P.P: 72 - 914.

Wiersma, S.K. (1969). Evaporative cooling fundamentals in agricultural application. ASAE paper presented at the tunnel convention-specific cost region. Poneix, Arizona. Mar. 20-21.

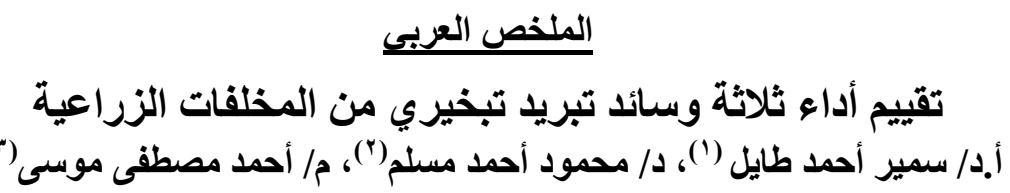

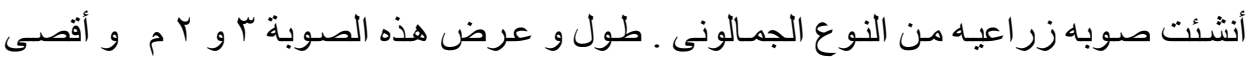

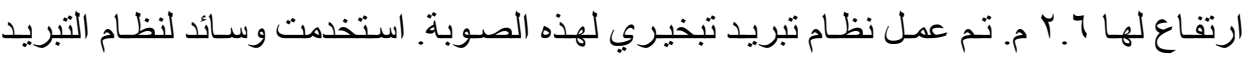

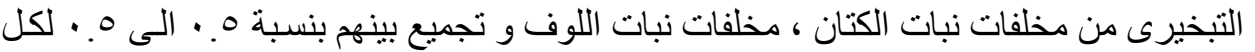

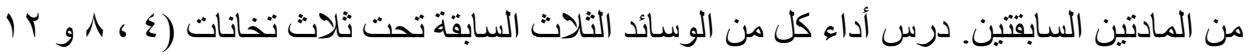

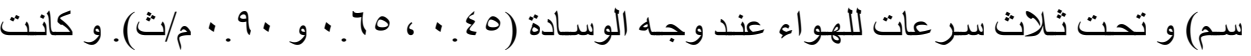
النتائج كالتالي:

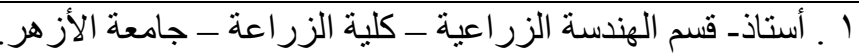

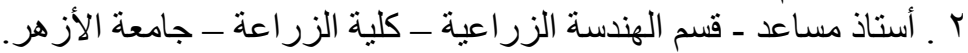

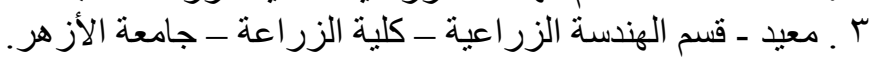




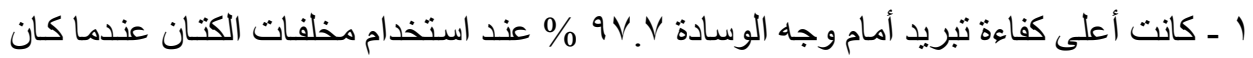

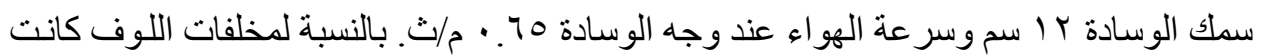

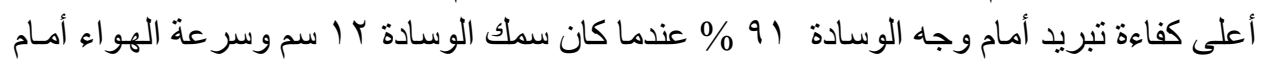

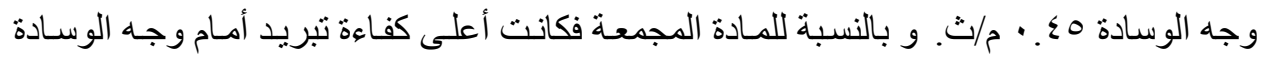

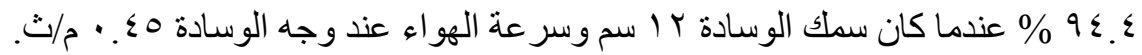

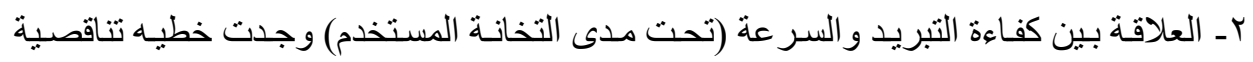

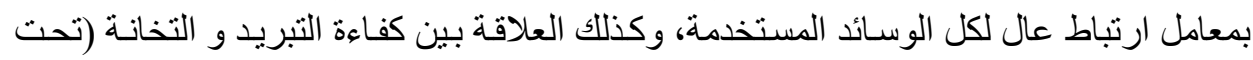

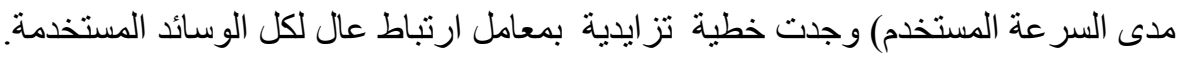

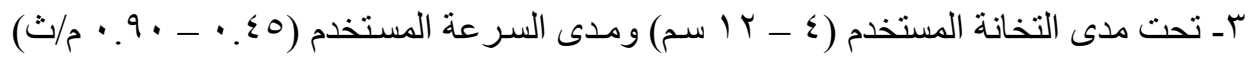

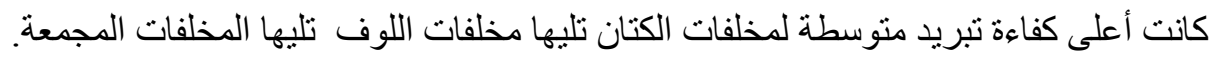

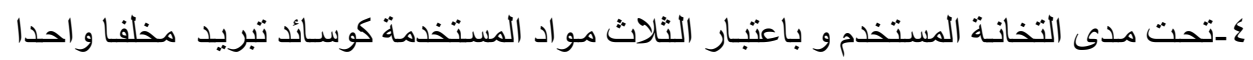

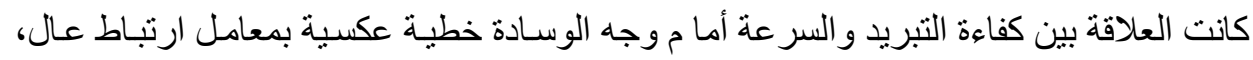

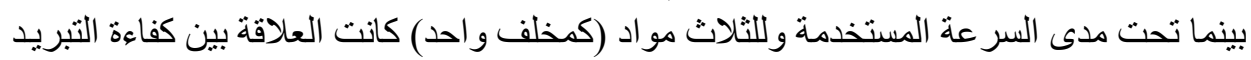

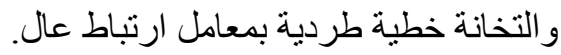

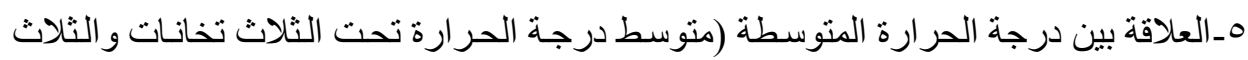

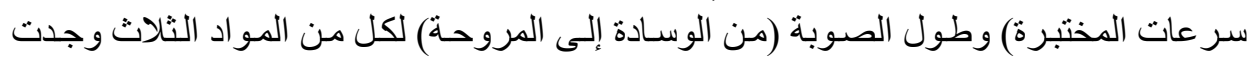

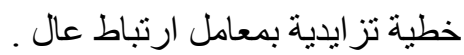

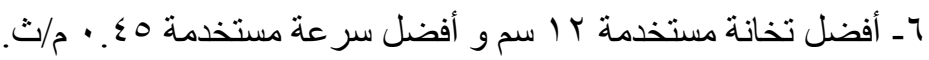

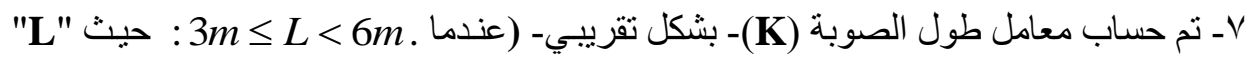

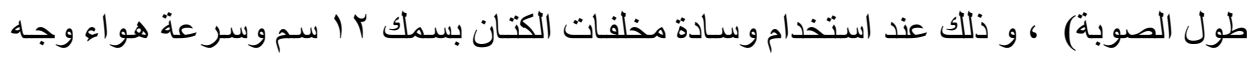

$$
K=12.302 L^{-0.7779} \quad R^{2}=0.92
$$

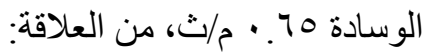

\section{APPENDIX}

Table (2): Values of the distance correcting Factor "K".

\begin{tabular}{|c|c|c|c|c|c|}
\hline $\begin{array}{c}\text { Distance } \\
(\mathrm{L}), \text { in } \mathrm{m}\end{array}$ & $\mathrm{K}$ & $\begin{array}{c}\text { Distance } \\
(\mathrm{L}), \text { in } \mathrm{m}\end{array}$ & $\mathrm{K}$ & $\begin{array}{c}\text { Distance } \\
(\mathrm{L}), \text { in } \mathrm{m}\end{array}$ & $\mathrm{K}$ \\
\hline 6.0 & 2.24 & 15.0 & 1.41 & 24.0 & 1.12 \\
\hline 7.7 & 2.00 & 16.5 & 1.35 & 25.5 & 1.08 \\
\hline 9.0 & 1.83 & 18.0 & 1.29 & 27.0 & 1.05 \\
\hline 10.5 & 1.69 & 19.5 & 1.24 & 28.5 & 1.02 \\
\hline 12.0 & 1.58 & 21.0 & 1.20 & 30.0 & 1.00 \\
\hline 13.5 & 1.48 & 22.5 & 1.16 & $\ldots \ldots \ldots$ & $\ldots \ldots$ \\
\hline
\end{tabular}

